تأثير اضافة كل من مخاليط الانزيمات العلقية (Poultrygrow 250) أو كروم الخميرة في الاداء الانتاجي ويعض المؤثرات الصحية لفروج اللحم.

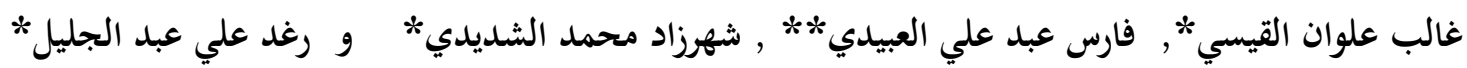

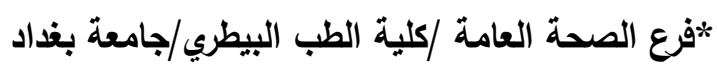

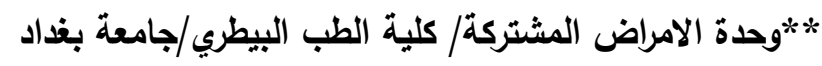
الخلاصــــة

تم استخدام (300) فرخ لحم بعمر يوم واحد غير مجنسة موزعة على ثلاثة مجاميع تغذوية هي:

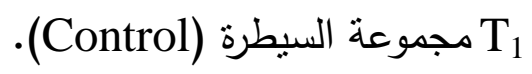
Tجموعة اضافة خليط الانزيمات العلفية (Poultrygrow 250).

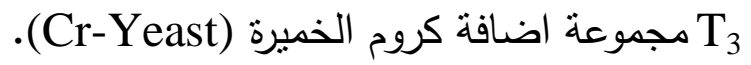

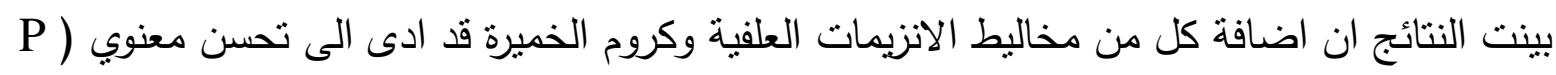
0.05 >) في الصفات الانتاجية متمثلة بالوزن الحي والزيادة الوزنية مع التحسن في معامل التحويل

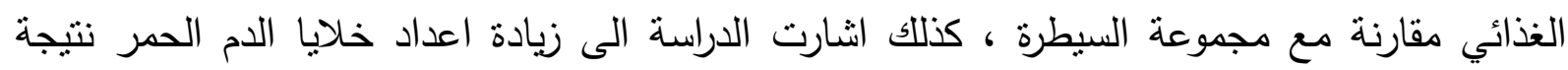

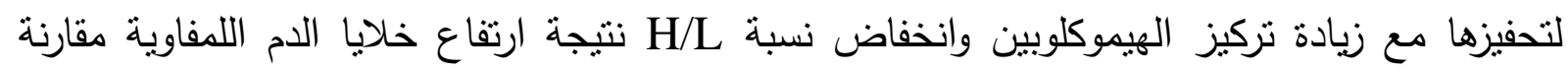

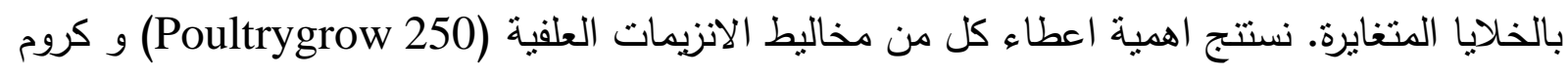
الخميرة (Cr-Yeast) في علائق دجاج اللحم لتحسين الاداء الانتاجي.

\title{
Effect of Adding Poultrygrow 250 and Cr-Yeast in the Productive Performance and Some Health Aspects of Broiler Chicks
}

\section{Galib. A. AL-Kassi*, Faris A. Al-Obaidi**, Shahrazad A. Al-Shadeedi*}

\section{and Raghad A. Abd Al-Jaleel*}

* Dept. of Public Health, College of Vet. Med.,Baghdad Universit

** Zoonosis unit, College of Vet. Med.,Baghdad University.

\section{Summary}

A total of 300 one day old unsexed broiler chicks were divided into three dietary groups which were: -

$\mathrm{T}_{1}$ : Un-treated control.

$\mathrm{T}_{2}$ : Poultrygrow 250 treated group.

$\mathrm{T}_{3}$ : Cr-Yeast treated group. 
Results have shown that the addition of Poultrygrow 250 and Cr-Yeast have significantly $(\mathrm{p}<0.05)$ improved the performance of broilers express in weight gain and feed conversion ratio compared with control group. The study showed an increase in red blood cell and hemoglobin and reduce in hetrophil / Lymphocyte ratio.It was concluded that the supplementation of poultrygrow 250 and Cr-Yeast in the diet of broiler chickens could improve the performance of the birds.

\section{المقدمــة}

لقد شهدت صناعة الدواجن تطوراً كبيرا وسريعاً في مختلف حلقاتها وبما ان التغذية من اهم هذه

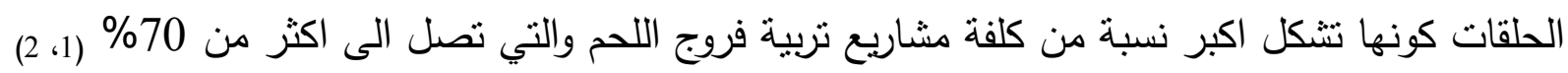
الامر الذي ادى الى اهتمام المختصين في تغذية الطيور الداجنة ومنها اضافة مخلوط الانزيمات العلفية

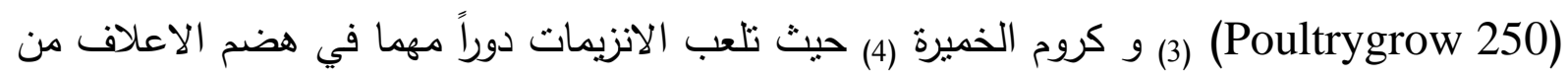

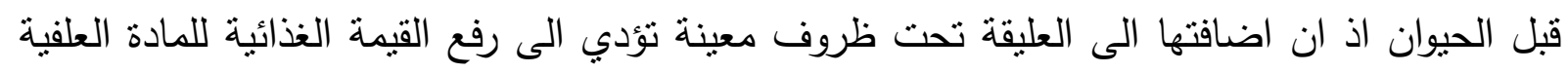

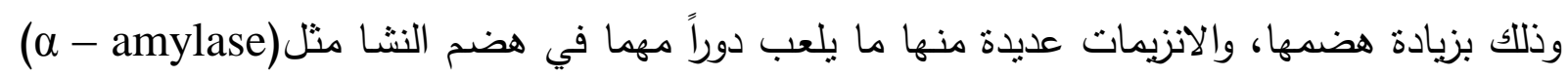

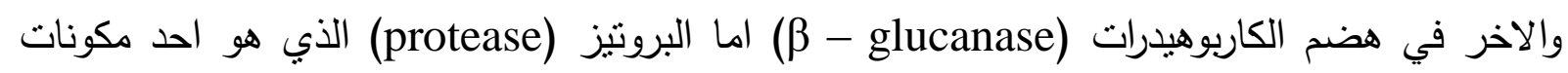

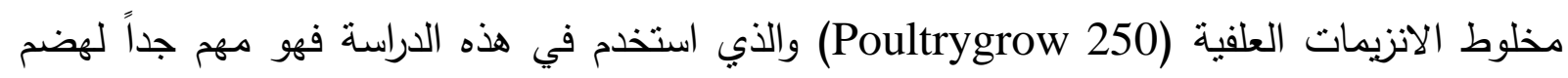

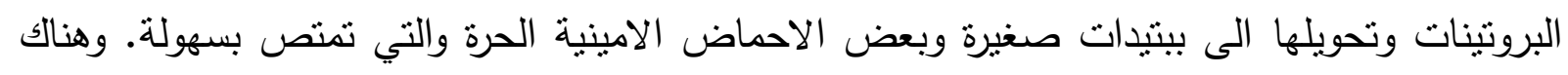

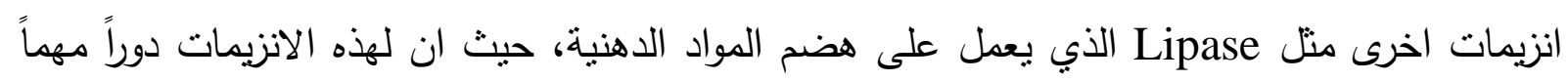

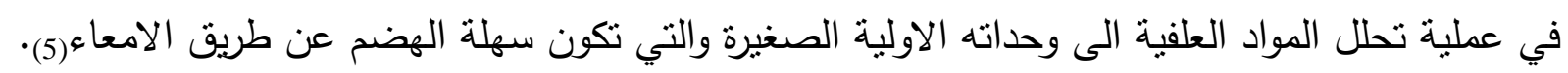

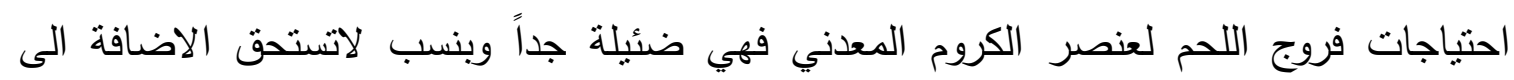

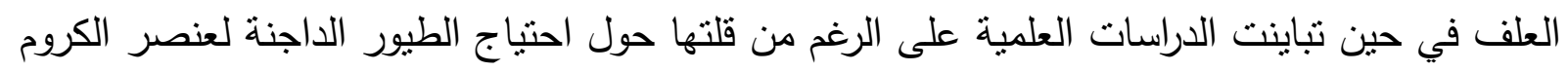

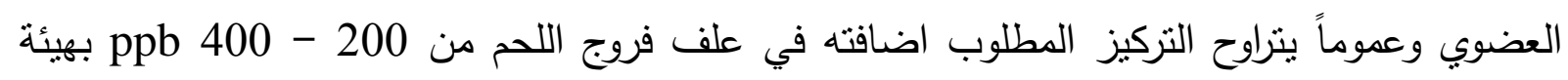
عiocolinate

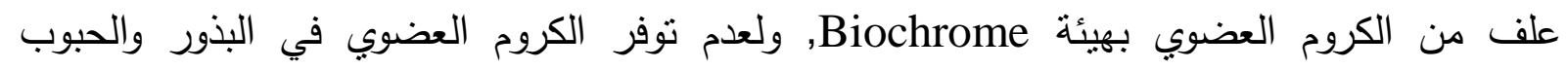

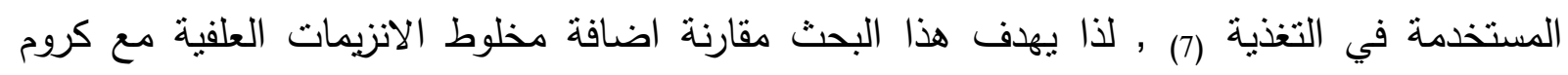

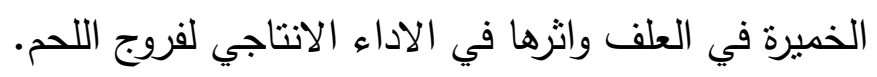




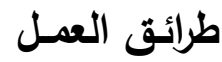

جريت هذه الدراسة في حقل الدواجن التابع الى كلية الطب البيطري- جامعة بغداد للفترة من 3/ 4 لغاية 3/ 6/ 2005 لدراسة تأثثير اضافة مخلوط الانزيمات العلفية (Poultrygrow 250) وكروم الخميرة التجاري (Cr-yeast) في الاداء الانتاجي وبعض المؤشرات الصحية لفروج اللحم. استخدمت في هذه

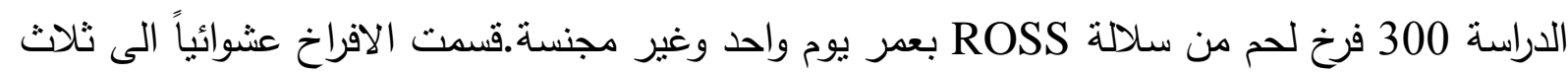

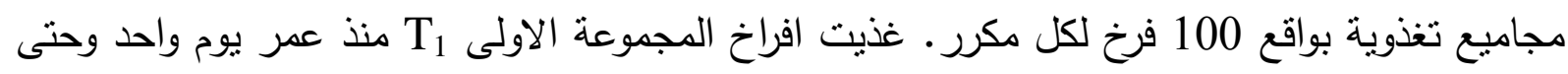
انتهاء مدة التجربة على عليقة موحدة حاوية على عليقة احتوت 21.49\% بروتين خام وطاقة ممثلة 3188 كيلو سعرة لكل كيلو غرام علف و تم اضافة مخلوط الانزيمات العلفية (Poultrygrow 250) الى نفس العليقة في المجموعة الثانية T2 بواقع 125 غرام/ للطن الواحد اما المجموعة الثالثة اضافة كروم الخمبرة التجاري (Cr-yeast) بواقع 400 جزء بالبليون الى نفس العليقة.

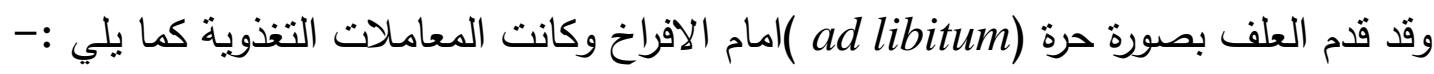
المجموعة الاولى T Tمموعة السيطرة(بدون اي اضافات غذائية). المجموعة الثانية T2 العليقة القياسية+ خليط الانزيمات العلفية. المجموعة الثالثة Th العليقة القياسية+ كروم الخميرة التجاري. خليط الانزيمات العلفية Poultrygrow 250 لقد تم تحديد جرعة خليط الانزيمات العلفية Poultrygrow 250 المصنع من قبل شركة

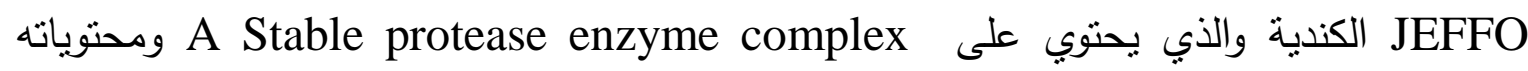

Protease (Min) $1000000 \mathrm{CPU} / \mathrm{kg}$ Crude Protein (Min) $15.0 \%$ Crude Fat (Min) $3.5 \%$ Crude Fiber (Min) $5.5 \%$

كروم الخميرة التجاري (Cr-Yeast) :تم استخدام كروم الخميرة Cr-yeast والمسمى تجاريا Biochrome والمنتج من قبل شركة Alltech LTD ، ويجهز الغرام الواحد منه 100 ملغم كروم عضوي ثلاثي التكافؤ (3) (Cr).

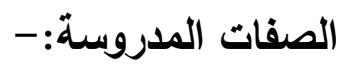


وزنت الافراخ بصسورة فراديـة اسبوعياً كما تم حسـاب معدل الزيادة الوزنية ثم حسبت كميـة العلف

المستهلك في نهاية الفترة لحساب كفاءة التحويل الغذائي وتم حساب اعداد الافراخ الهالكة لحساب نسبتها المئوية للهاكات.

\section{فحوصات الام الخلوية}

جمعت عينات الدم مـع مواعيد تشريح الافراخ وجمع الدم من فرخ واحد من كل معاملة وبصورة عشوائية ـ اذ جمع الدم من الوربد العضدي Brachial vein حيث استخدمت انابيب حاوية على مانع تخثر Potassium EDTA لمنع تخثر الدم وتم اعتماد المعدلات العامة خلال مرات الجمع لقياس تركيز الهيموغلوبين وحسب الطريقة التي اثنار اليها (8) و قدرعدد خلايا الدم الحمروالبيض واعداد الخلايا المتغايرة (Heterophils) والخلايا الامفاوية (Lymphocytes) لاستخراج نسبة اعداد الخلايا المتغايرة الى اعداد الخلايا اللمفاوية (H/L ratio) وفقاً للطرق التي اشار اليها (9) وثم قياس النسبة المئوية لحجم خلايا الدم المرصوصة حسب الطربقة التي اثار البها (10) • التحليل الاحصائي:-

استخدم التصميم العشوائي الكامل (CRD) في تحليل البيانات , وقورنت الفروق

المعنوية بين المتوسطات باختبار اقل فرق معنوي واستخدم البرنامج SAS (11) في التحليل الاحصائي.

\section{النتائج والمناقشة}

يتضح من الجدول 1 عدم وجود فروقات معنوية (0.05) في معدل الوزن الحي للافراخ عند عمر الاسبوع الاول وهذا يعود الى التوزيع العشوائي للافراخ وعدم تاثير كل من مخلوط الانزيمات العلفية وكروم الخميرة التجاري لقلة المدة المستخدمة في التجربة، في حين ظهرت فروقات احصائية (0.05>م) بين معاملات التجربة ابتداءً من الاسبوع الثاني ولحين انتهاء التجربة بعمر 49 يوم. حيث تقوقت

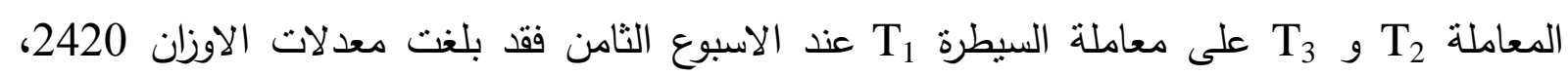
2680، 2620 غم على التوالي. ان التفوق الحاصل في الوزن الحي للطيور المغذاة على علف يحتوي على كل من خليط الانزبمات العلفية وكروم الخميرة التجاري كون ان مخلوط الانزبمات العلفية ادى الى زيادة معامل هضم الموادج العلفية داخل القناة الهضمية مما ادى الى زيادة امتصاص بقية المواد الغذائية عبر جدارها (12 و 13) هذا وقد اثنارت الدراسات الى ان وجود الطعام في الامعاء يزبد من افراز الغدة المعدية التي بدورها تزبد من امتصاص الكتلة الغذائية والاستفادة منها وبالتالي زيادة وزن الجسم الحي (14)• كما ان للمعزز المناعي الحاوي على الكروم (Cr+3) دور كبير في زيادة وزن الجسم عموما والطيور الداجنة بشكل خاص فضلاً على دور الكروم في تعزيز الحالة الصحية والمناعية عند وجوده مرتبطاً مع 
المواد العضوية والاحماض الامينية، فالتحسن الذي حصل في معاملة اضافة كروم الخميرة والذي يعود

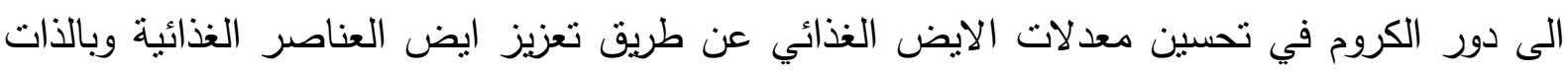

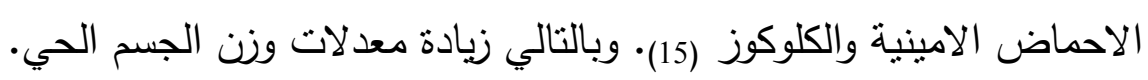

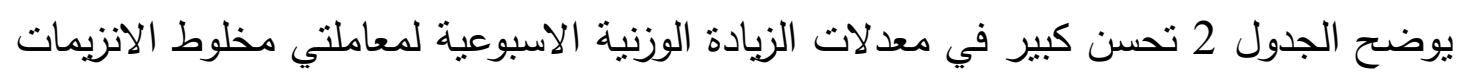

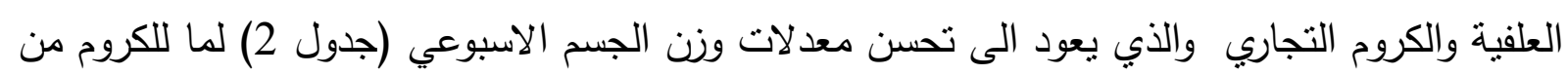
اثر كبير في تحسين معدلات النمو لفروج اللحم (6 و 16).

جدول 1 تأثير اضافة كل من مخلوط الانزيمات العلقية (Poultrygrow 250) وكروم الخميرة التجاري (Cr-yeast) في معدل الوزن الحي الاسبوعي (غم) لفروج اللحم \pm الخطأ القياسي.

\begin{tabular}{|c|c|c|c|c|c|c|c|c|}
\hline 49 يوم & 42 يوم & 35 يوم & 28 يوم & 21 يوم & 14 يوم & 7 ايام & يوم واحد & المعاملات \\
\hline a & $\mathbf{a}$ & $\mathbf{a}$ & $\mathbf{a}$ & & $\mathbf{a}$ & & & $\mathbf{T}_{1}$ \\
\hline 2420 & 1867 & 1320 & 942 & 574 & $8.24 \pm \mathbf{3 0 0}$ & 92 & & السيطرة \\
\hline $38.16 \pm$ & $22.76 \pm$ & $21.07 \pm$ & $13.44 \pm$ & $10.05 \pm$ & & 1.12 & 0.41 & \\
\hline b & b & b & b & & b & & & $\mathbf{T}_{2}$ \\
\hline 2680 & 2160 & 1468 & 998 & 580 & $5.14 \pm \mathbf{3 4 0}$ & & & مخلوط \\
\hline $33.86 \pm$ & $25.17 \pm$ & $28.20 \pm$ & $12.85 \pm$ & $6.54 \pm$ & & 0.67 & 0.32 & الانزيمات \\
\hline & & & & & & & & العلفية \\
\hline b & b & b & $\mathbf{a b}$ & & b & & & $\mathbf{T}_{3}$ \\
\hline 2620 & 2137 & 1413 & 985 & 583 & $7.84 \pm \mathbf{3 6 0}$ & $0.62 \pm 99$ & $0.26 \pm 44$ & كروم \\
\hline $35.22 \pm$ & $28.17 \pm$ & $20.12 \pm$ & $11.34 \pm$ & $15.49 \pm$ & & & & الخميرة \\
\hline$*$ & $*$ & * & $*$ & N.S. & $*$ & N.S. & N.S. & المعنوية \\
\hline
\end{tabular}

• المتوسطات التي تحمل حروفاً مختلفة ضمن العمود الواحد تختلف معنوياً فيما بينها (P>0.01). 
جدول (2) تأثير اضافة كل من مخلوط الانزيمات العلفية (Poultrygrow 250) وكروم الخميرة التجاري (Cr-yeast) في معدل الزيادة الوزنية لاسبوعية والتراكمية (غم) لفروج اللحم \pm الخطأ القياسي.

\begin{tabular}{|c|c|c|c|c|c|c|c|c|}
\hline التراكمية & 49 يوم & 42 يوم & 35 يوم & 28 يوم & 21 يوم & 14 يوم & 7 ايام & المعاملات \\
\hline $\begin{array}{r}\mathbf{a} \\
2377^{-1} \\
41.29 \pm\end{array}$ & $\begin{array}{c}553 \\
32.82 \pm\end{array}$ & $\begin{array}{r}\mathbf{a} \\
\mathbf{5 4 7} \\
31.30 \pm\end{array}$ & $\begin{array}{c}\mathbf{a} \\
\mathbf{3 7 8} \\
23.40 \pm\end{array}$ & $\begin{array}{r}\mathbf{a} \\
\mathbf{3 6 8} \\
11.20 \pm\end{array}$ & $\begin{array}{r}\mathbf{a} \\
8.40 \pm 274\end{array}$ & $\begin{array}{c}\mathbf{a} \\
208 \\
1.08 \pm\end{array}$ & $0.38 \pm 49$ & $\begin{array}{c}\mathbf{T}_{1} \\
\text { السيطرة }\end{array}$ \\
\hline $\begin{array}{r}\text { b } \\
2637 \\
39.63 \pm\end{array}$ & $\begin{array}{c}520 \\
18.20 \pm\end{array}$ & $\begin{array}{r}\text { b } \\
692 \\
34.60 \pm\end{array}$ & $\begin{array}{c}\text { b } \\
470 \\
21.06 \pm\end{array}$ & $\begin{array}{r}\text { b } \\
9.27 \pm 418\end{array}$ & $\begin{array}{r}\text { b } \\
7.20 \pm 240\end{array}$ & $\begin{array}{r}\text { b } \\
0.98 \pm 245\end{array}$ & $0.34 \pm \mathbf{5 2}$ & $\begin{array}{c}\mathbf{T}_{2} \\
\text { الانزيمات العلقية } \\
\text { العظوط }\end{array}$ \\
\hline $\begin{array}{r}\text { b } \\
2576 \\
31.12 \pm\end{array}$ & $\begin{array}{c}483 \\
23.12 \pm\end{array}$ & $\begin{array}{r}\text { b } \\
29.6 \pm 724\end{array}$ & $\begin{array}{c}\mathbf{a b} \\
\mathbf{4 2 8} \\
18.92 \pm\end{array}$ & $\begin{array}{c}\text { ab } \\
402 \\
10.17 \pm\end{array}$ & $\begin{array}{r}\text { b } \\
6.80 \pm 223\end{array}$ & $\begin{array}{r}\text { c } \\
0.84 \pm 261\end{array}$ & $0.26 \pm \mathbf{5 5}$ & $\begin{array}{c}\mathbf{T}_{3} \\
\text { كروم الخميرة }\end{array}$ \\
\hline$*$ & N.S. & $*$ & $*$ & $*$ & $*$ & $*$ & N.S. & المعنوية \\
\hline
\end{tabular}

• المتوسطات التي تحمل حروفاً مختلفة ضمن العمود الواحد تختلف معنوياً فيما بينها (p>01).

اما بالنسبة للجدول 3 فقد ادت اضافة كل من مخلوط الانزيمات العلفية وكروم الخميرة التجاري

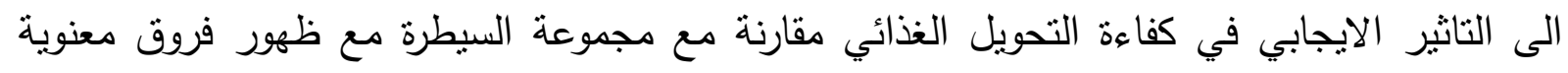

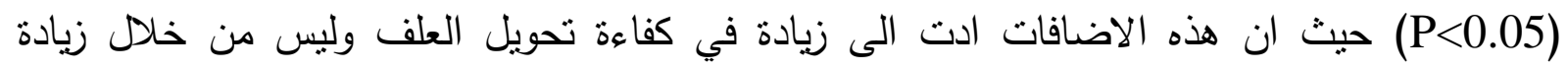

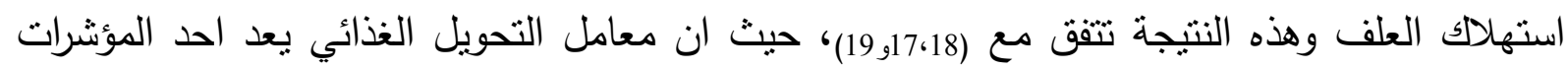

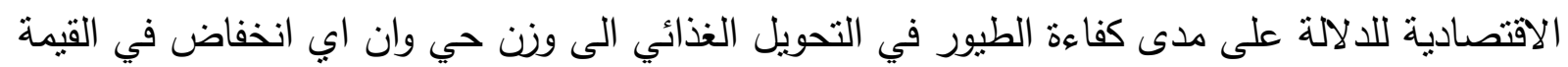

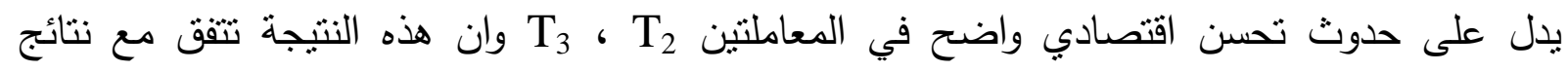

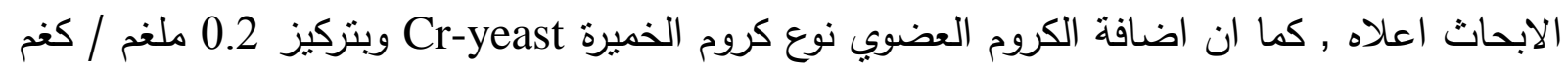


علف من شانه ان بعمل على تحسن في ايض العناصر الغذائية فضلا عن زيادة الاستفادة من الغذاء المتتاول وبالتالي تحسين معامل التحويل الغذائي (20).

جدول (3) تأثير اضافة كل من مخلوط الانزيمات العلفية (Poultrygrow 250) وكروم الخميرة التجاري (Cr-yeast) في معامل التحويل الغذائي الاسبوعي لفروج اللحم 土 الخطأ القياسي.

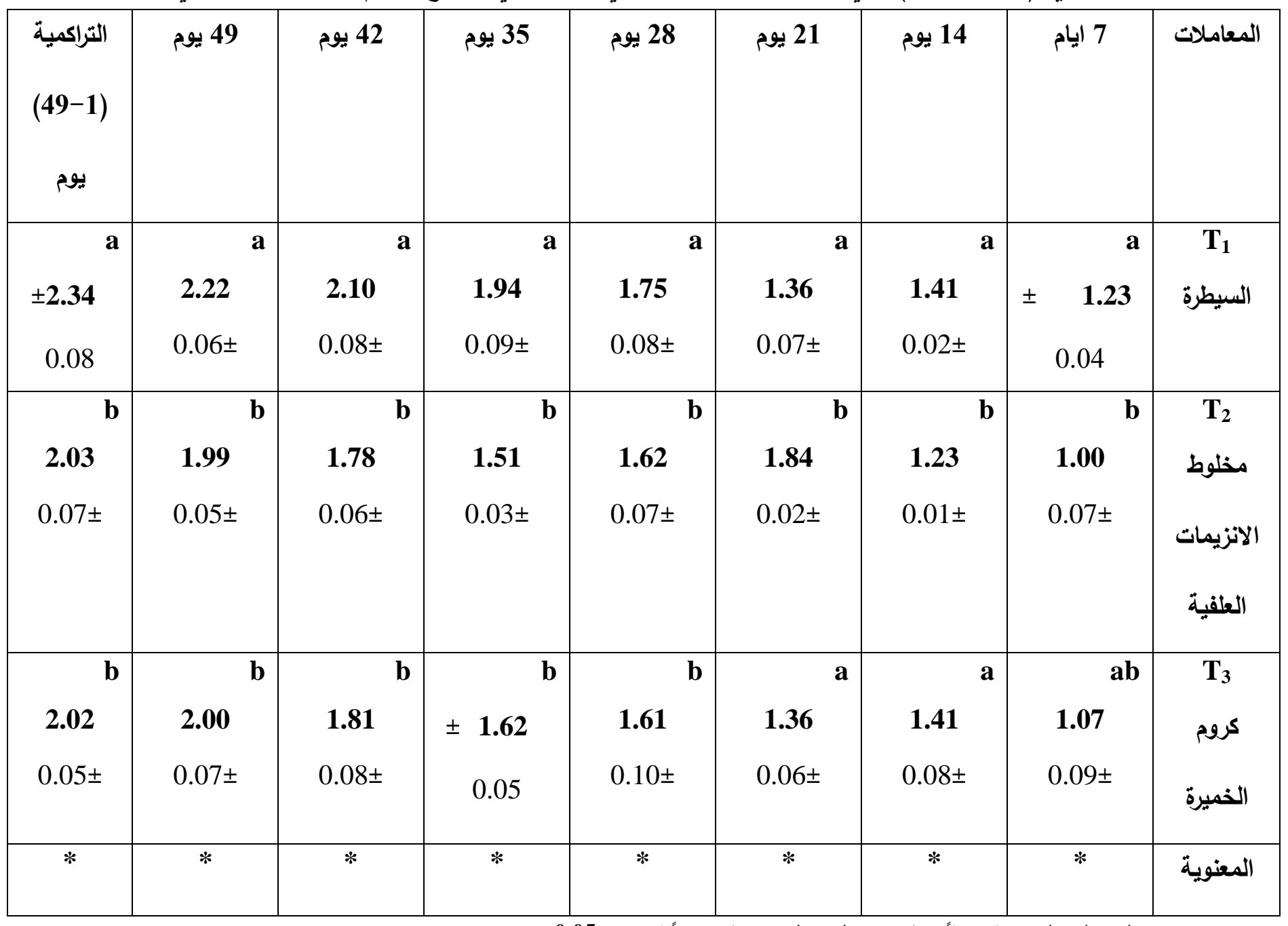

يتضح من الجدول 4 وجود فروقات معنوية احصائياً (0.05>p) في الصفات الخلوية للام عند

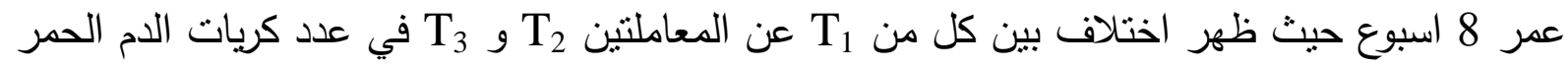

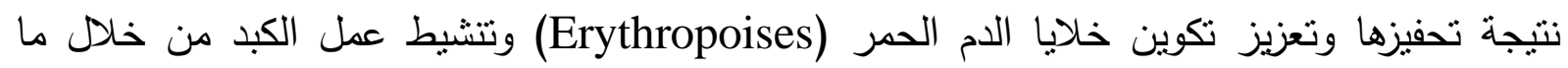
تفرزه من انزيمات منشطة والذي بدوره يقوم بتحفيز الكلية على افراز هرمون Erythropoitein المحفز

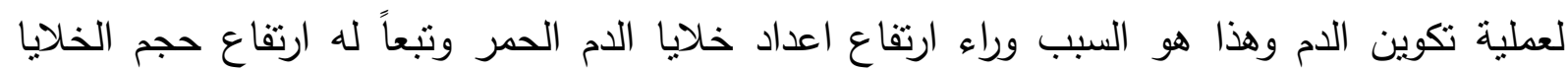
المرصوصة (PCV) ذلك ان هذا المقياس يعتمد بالدرجة الرئيسية على اعداد الخلايا الحمر، ونتيجة 
لذلك يزداد تركيز هيموغلوبين الدم (Hb) ذلك ان هذا الاخير هو بروتين محمول على خلايا الدم الحمر. ويزداد بزيادة اعدادها والعكس صحيح (21) مغرين

ان الانخفاض الحاصل في نسبة H/L يشير الى ارتفاع في اعداد الخلايا اللمفاوية مقارنة

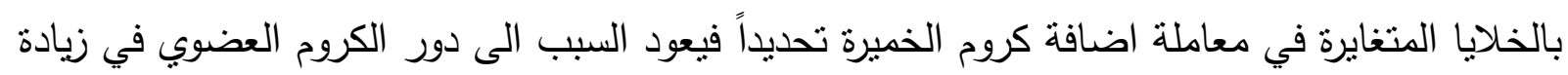
الاستجابة المناعية لفروج اللحم المغذى على علف يحويه بسبب دوره في زيادة اعداد الخلايا اللمفاوية

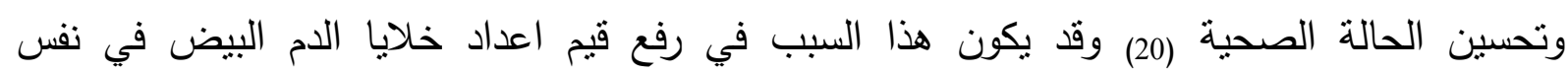
المعاملة.

جدول 4 تأثير اضافة كل من مخلوط الانزيمات العلفية (Poultrygrow 250) وكروم الخميرة التجاري (Cr-yeast) على الصفات الخلوية للام عند عمر (8) اسبوع 土ـ الخطأ القياسي.

\begin{tabular}{|c|c|c|c|c|c|c|c|}
\hline $\begin{array}{l}\mathrm{H} / \mathrm{L} \\
\text { ratio }\end{array}$ & $\begin{array}{c}\text { Lymph- } \\
\text { ocytes \% }\end{array}$ & \begin{tabular}{c}
\multicolumn{2}{c}{ Heter - } \\
ophils \%
\end{tabular} & $\begin{array}{l}\text { W.B.C } \\
\text { الف / مل }\end{array}$ & 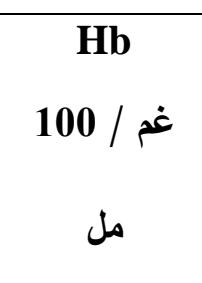 & PVC \% & $\begin{array}{c}\text { RBC } \\
\text { مليون / مل }\end{array}$ & المعاملات المدروسة \\
\hline $\begin{array}{r}\mathbf{a} \\
0.01 \pm \mathbf{0 . 3 1}\end{array}$ & $\begin{array}{r}\text { c } \\
0.33 \pm 61.9\end{array}$ & $\begin{array}{l}19.2 \\
0.01 \pm\end{array}$ & $\begin{array}{l}\text { b } \\
\mathbf{2 4 . 2 1} \\
0.01 \pm\end{array}$ & $\begin{array}{r}\text { b } \\
0.03 \pm \mathbf{8 . 5 7}\end{array}$ & $\begin{array}{l}\mathbf{a} \\
\mathbf{3 5 . 3 3} \\
0.33 \pm\end{array}$ & $\begin{array}{l}\mathbf{3 . 3 1}^{\mathbf{b}} \\
0.04 \pm\end{array}$ & $\begin{array}{c}\text { T } \\
\text { السيطرة }\end{array}$ \\
\hline $\begin{array}{r}\mathbf{a} \\
0.01 \pm \mathbf{0 . 3 0}\end{array}$ & $\begin{array}{r}\text { b } \\
0.58 \pm 67.7\end{array}$ & $0.02 \pm \mathbf{2 0 . 3}$ & $\begin{array}{l}\text { b } \\
\mathbf{2 4 . 2 3} \\
0.02 \pm\end{array}$ & $\begin{array}{r}\mathbf{b} \\
0.01 \pm \mathbf{8 . 6 0}\end{array}$ & $\begin{array}{l}\mathbf{a} \\
\mathbf{3 6 . 0 0} \\
0.58 \pm\end{array}$ & $\begin{array}{l}\mathbf{3 . 3 5} \\
0.02 \pm\end{array}$ & $\begin{array}{c}T_{2} \\
\text { الانزيمات } \\
\text { العظوطة }\end{array}$ \\
\hline $\begin{array}{r}\mathbf{b} \\
0.01 \pm \mathbf{0 . 2 7}\end{array}$ & $\begin{array}{r}\mathbf{a} \\
0.01 \pm \mathbf{7 1 . 9}\end{array}$ & $0.06 \pm \mathbf{1 9 . 4}$ & $\begin{array}{l}\mathbf{a} \\
\mathbf{2 4 . 3 6} \\
0.06 \pm\end{array}$ & $\begin{array}{r}\mathbf{a} \\
0.01 \pm \mathbf{8 . 7 0}\end{array}$ & $\begin{array}{l}\mathbf{a} \\
\mathbf{3 6 . 0 0} \\
0.01 \pm\end{array}$ & $\begin{array}{l}\mathbf{3 . 4 0} \\
0.01 \pm\end{array}$ & $\begin{array}{c}\mathbf{T}_{3} \\
\text { كروم الخميرة }\end{array}$ \\
\hline 0.009 & 2.03 & N.S. & 0.124 & 0.066 & 1.33 & 0.084 & L.S.D. \\
\hline
\end{tabular}


المصادر

1. Kamara, M.; T.N. Pasha; A. Mahmud and Z. Ali (2002). Effect of commercial Enzyme (Natugrain) supplementation on the nutritive value and inclusion rate of guar meal in broiler rations. In. J. of Poult. Sci., 1: (6) 167 173.

2. Esonu, B.O., J.C. Azubuike; O.O. Emenlaom; E.B. Etuk; IC. Okoli; Ukwu and C.S. Nnegi (2004). Effect of enzyme supplementation on the performance of broiler finisher feed microdesmis puberula leaf meal. In. J. of Poult. Sci., 3 (2): 112 - 114.

3. Alam, M.J.; M.A.R. Gowlider; M.A.H. Pramanik and M.A. Hapue (2003). Effect of exogenous enzyme in diet on broiler performance. In. J. of Poult. Sci., 2 (2): $168-173$.

4. Lindemann, M.D.; C.M., Wood; A.F., Harper, E.T. Komegay and R.A., Anderson (1995). Dietary chromium picolinate additions improve gain / feed and carcass characteristics in growing finishing pigs and increase litter size in reproduction sows. J. Anim. Sci. 73: 457 - 465.

5. Ward, T.L., L.L, Southern and S.L. Boleman. (1993). Effect of dietary chromium picolinate on growth, nitregen balance and body composition of growing broiler chicks. Poultry Sci. 72: (Suppl. 1): 37.

6. Hossian, S.M.; S.L. Barreto, and C.G. Silva, (1997). Growth performance and carcass composition of broiler fed supplementation chromium from chromium yeast. Animal Feed Science and Technology.

7. National Research Council. (1994). Nutrient Requirement of Poultry. 9th ed. National Academy Press. Washington, DC.

8. Varley,H.A.H.GrawenlockandM.Bell.(1980).PracticalClinical Biochem istry 5thed William Heinemann Medical Books.Ltd.,London.

9. Natt M.P. and C.A. Herrick(1952).A new blood diluent for counting the erythrocytes and Leukocytes of the chicken.Poultry Sci.31:735- 738.

10. Archer,P.K.(1965).Haematological techniques for use in animals Oxford Black Scientific Publications.

11.SAS, (1996). SAS User'sGuide: Statistical System, Inc. Cary, NC. USA.

12.Broze, J. and M. Frigg, (1986). Effect of beta glucanase on the feeding value of broiler diets based on barley or oats. Arch. Gefiugelk. 50: $41-47$ (Abstr.) Cited by Bell and Bradley, 1989).

13.Hasselman, K. and P. Aman, (1986). A note on microscopy studies on water and $\beta$-glucanase - treated barley. Swed. J. Agric. Res 15: $139-143$.

14.Davis, C.K., H. Michele, Sumral and J.B. Vincent. (1996). A biological active a membrane physphotyrosine phosphate (ptp). Biochem 35: 12963.

15.Hossain, S.M. (1995). Effect of chromium yeast on performance and carcass quality of broiler. Alltechs Elerenth Ann. Symp. Poster. Presentation. 
16.Cantor, A.H., A.J. Pescatore, T.H., Jhonson, and W.K. Pfaff, (1989). Influence of beta - glucanase additions to barley - based diets for broiler chicks. Poultry Sci. 68: 24 (suppl.).

17.Ferket, P.R., C.E., Brewer, and J.L. Crimes (1989). Effect of level of supplemental $\beta$-glucanase in barley - soy diets on performance markets turkey tom. Poultry Sci. 68: 181 (suppl.).

18.المفرجي، عبد الكريم جسام راضي (1998). تقييم فسيولوجي لاضافة الانزيمات الهاضمة للشعير في دجاج اللحم. اطروحة دكتور اه - كلية الطب البيطري - جامعة بغداد.

19.Bhatt, R.S.; B.S. Katoch; K.K Dogra; R. Gupta; and K.S. Sharma (1995). Effect of dietary supplementation of different strain of Saccharomyces cerevisiae on the biological performance of broiler. Indian. J. of Anim. Nutri. 12: $60-64$.

20. الثديدي، شهزاد محمد والقيسي غالب علوان و زينب عبد الزهرة (2005). مقارنة استخدام

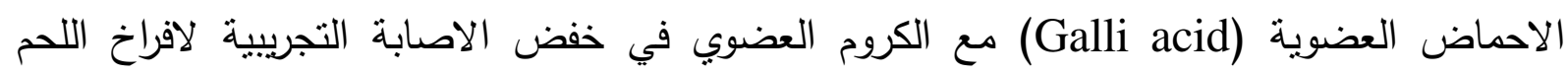
بجراثيم Salmonella typhimurium. مؤتمر الامراض المشتركة السادس للفترة 20 - 21 / 12 | 2005. كلية الطب البيطري.

21. Sturkie, P.D. (1986). Avian Physiology. $4^{\text {th }}$ Ed. New York Heldelberg Berlin Springer Verlage. 